\title{
Differentiation of spontaneous activity from normal and denervated skeletal muscle
}

\author{
R HECKMANN, * HP LUDIN $\dagger$ \\ From the Department of Veterinary Surgery, University of Zürich* and the Neurological Clinic, \\ University of Berne, Inselspital, Berne, $\uparrow$ Switzerland
}

SUMMARY The discrimination of fibrillation potentials and endplate potentials based on the conventional EMG methods is difficult if there is only discrete denervation. The reliability of discrimination can be highly improved if the frequency behaviour of the potentials is taken into account.

The average proportional consecutive interval difference is the best discrimination variable with $90 \%$ correct findings per analysed potential sequence. When three analyses per muscle are made, the accuracy increases to $97 \cdot 2 \%$. The second best variable is the mean consecutive difference followed by interval bandwidth, standard deviation of interval, minimum interval and finally maximum interval. The mean duration of intervals does not allow of any differentiation. The frequency analysis can be restricted to spontaneous activity sequences of ten seconds. It is immaterial which part of a prolonged sequence is analysed for ten seconds. The conventional evaluation of registered spontaneous activity either alone or with observation at the monitor under simultaneous acoustic control is inferior to the frequency analysis. The results do not allow a statement of the probability of wrong diagnosis in clinical routine work.

A few days after axonal nerve lesion skeletal muscles exhibit spontaneous activity consisting of fibrillation potentials, positive sharp waves and possibly of pseudomyotonic bursts. ${ }^{1-7}$ The fact that such spontaneous activity may be found also in clinically normal muscle makes it obvious that it is important for electromyographic diagnosis to know by which criteria normal and pathological spontaneous activity may be differentiated. ${ }^{4}$ Jones et al ${ }^{4}$ pointed out that not only the shape of spontaneous potentials should be characterised but also their frequency behaviour. Conrad et $a l^{8}$ showed that in partially denervated human muscle most of the fibrillation potentials have an extremely regular firing frequency. Stöhr ${ }^{9}$ reported that fibrillation potentials can be considered as "malignant" (that is indicating denervation) when firing regularly. According to his observations it is impossible to distinguish fibrillation potentials on the basis of their shape only. His view is that the frequency behaviour is crucial for the discrimination between "benign" and "malignant"

Address for reprint requests: Dr HP Ludin, Neurological Clinic, University of Berne, Inselspital, Berne, Switzerland.

Received 27 August 1981

Accepted 30 October 1981 fibrillations. The last mentioned papers have the disadvantage that they are based on studies of only partially denervated and normally innervated muscles respectively. The present paper examined by which criteria spontaneous activity from normal and completely denervated skeletal muscle may be differentiated on the basis of shape and frequency parameters.

\section{Methods}

Spontaneous activity was recorded with concentric needle electrodes (surface of stigmatic electrode 0.07 $\mathrm{mm}^{2}$ ) from the interossei of one foreleg and from the extensor digitorum pedis brevis muscle of the same side from 16 clinically normal dogs under general anaesthesia without using any depolarising or non-depolarising muscle relaxants. These control muscles were examined only once to make sure that the muscles had not been damaged by previous needle insertions. At the same time the distal ulnar and peroneal nerves were sectioned on the contralateral side. After three, four and five days spontaneous activity was recorded from the completely denervated muscles. Before recording, the ulnar and peroneal nerves were electrically stimulated proximally and distally to the section site with square pulses. Whenever no compound potential could be elicited in the interossei and in the extensor digitorum pedis brevis 
muscles respectively, these were considered as being completely denervated. Spontaneous activity from totally denervated muscles was recorded 3, 4 and 5 days after neurectomy. For comparison with normal human muscle spontaneous activity was recorded from the thenar muscles in ten control persons aged between 20 and 36 years. All muscles, animal as well as human, were examined at an intramuscular temperature of $36^{\circ} \pm 1^{\circ} \mathrm{C}$.

The recorded electrical activity was registered on tape and then analysed in regard to shape and frequency behaviour. A total of 57 potentials sequences were analysed from control canine muscle, the respective numbers for denervated animal and for normal human muscles being 52 and 20. Each potential sequence was analysed for $10 \mathrm{~s}$. Preliminary studies with analysis times of up to $100 \mathrm{~s}$ showed that times longer than $10 \mathrm{~s}$ do not improve the reliability of frequency analysis. The following shape parameters were analysed: polarity of initial deflection from the base line, amplitude (peak-to-peak), total duration and number of phases. For characterising the firing behaviour the following values were computed: average value of the interval duration (ms), standard deviation of the time intervals (ms), APCID* according to Conrad et al, ${ }^{8} \mathrm{MCD} \dagger$ according to Stålberg et al, ${ }^{10}$ minimum and maximum interval duration (ms) and interval bandwidth (ms) (that is, maximum interval duration minus minimum interval duration). These firing parameters were computed by an apparatus especially built for that purpose (fig 1). It was then possible to register the interval behaviour on-line and subsequently to calculate all the variables listed above. In addition, time and interval histograms and potential sequences of various duration could be plotted (fig 2 ).

${ }^{*} \mathrm{APCID}=\frac{1000}{n} \sum_{i=2}^{n} \frac{1}{2}\left|\frac{\left(x_{i}-x_{i-1}\right) i}{\left(x_{i}+x_{i-1}\right)}\right|$

(APCID $=$ average proportional consecutive interval difference)

$\dagger \mathrm{MCD}=\frac{1}{2} \sum_{\mathrm{i}=2}^{\mathrm{n}}\left|\left(\mathrm{x}_{\mathrm{i}}-\mathrm{x}_{\mathrm{i}-1}\right)\right|$

$(\mathrm{MCD}=$ mean consecutive difference $)$
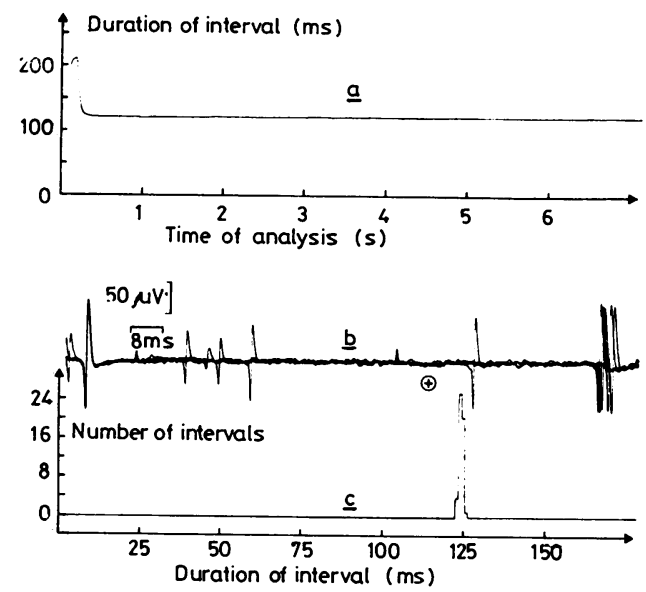

Fig 2 Typical interval behaviour of a fibrillation potential derived from a totally denervated muscle (the initial hump is due to an artefact). A interval behaviour versus time of analysis; B superposition of potentials of the analysed potential sequence; $C$ interval histogram.

In a further study 20 sequences of spontaneous activity each of $50 \mathrm{~s}$ duration were recorded on tape from control and from completely denervated muscles. This taped information was displayed to eight electromyographically trained physicians optically and acoustically on a conventional EMG machine. In addition they received paper recordings of $100 \mathrm{~ms}$ duration each taken from the same sequences. They were asked to judge whether the individual sequences were recorded from control or denervated muscles. This last study was carried out under double-blind criteria.

\section{Results}

Shape parameters (total duration of potentials (ms), polarity of the initial deflection from the base line, number of phases and amplitude (peak-to-peak,

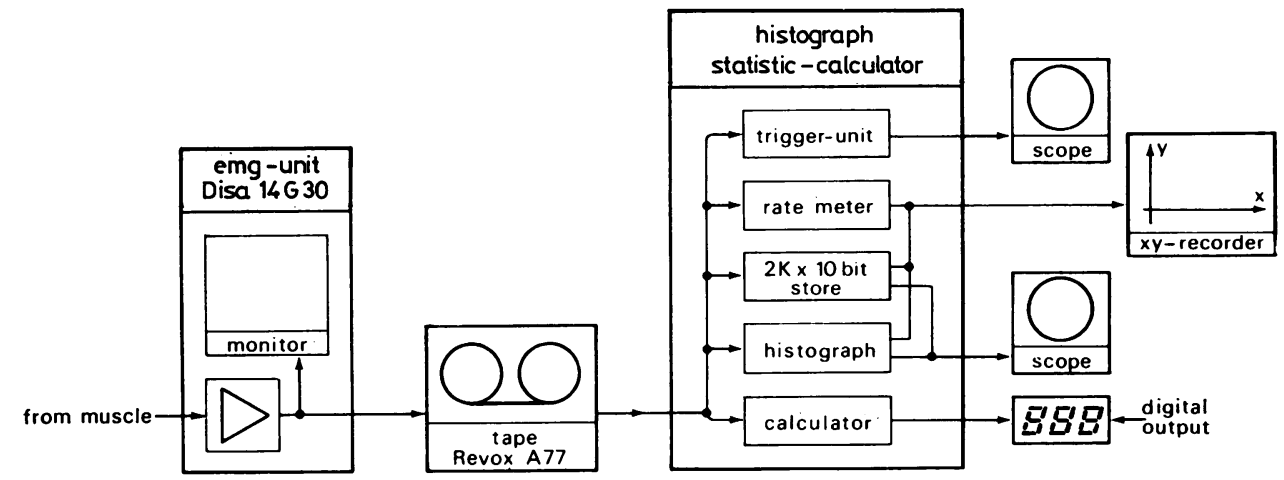

Fig 1 Block diagram of recording and analysing device. 
Table 1 Synopsis of shape parameters

\begin{tabular}{|c|c|c|c|c|c|c|c|c|}
\hline & \multirow[t]{2}{*}{$\begin{array}{l}\text { Total duration of } \\
\text { potentials }(\mathrm{ms})\end{array}$} & \multicolumn{2}{|c|}{$\begin{array}{l}\text { Polarity of initial } \\
\text { deflection }(\%)\end{array}$} & \multicolumn{4}{|c|}{ Number of phases } & \multirow[t]{2}{*}{$\begin{array}{l}\text { Amplitude (peak to } \\
\text { peak) }(\mu V)\end{array}$} \\
\hline & & Positive & Negative & 1 & 2 & 3 & $>3$ & \\
\hline \multirow{4}{*}{$\begin{array}{l}\text { Control (human) } \\
(\mathrm{n}=20) \\
\text { Control (dog) } \\
(\mathrm{n}=57) \\
\text { Denervated (dog) } \\
(\mathrm{n}=52)\end{array}$} & $4 \cdot 3 \pm 1 \cdot 1$ & 45 & 55 & 65 & 25 & 10 & - & $68 \pm 37$ \\
\hline & & & & & & & & \\
\hline & $5 \cdot 2 \pm 3 \cdot 4$ & 56 & 44 & 51 & 42 & 5 & 2 & $62 \pm 51$ \\
\hline & $5 \cdot 7 \pm 2 \cdot 4$ & 90 & 10 & 50 & 35 & 12 & 3 & $73 \pm 53$ \\
\hline
\end{tabular}

$\mu \mathrm{V})$ ) are listed in table 1 . The take-off from the base line is of special interest because only potentials with a positive initial deflection are considered to be pathological. ${ }^{1}$ In the present material $90 \%$ of the potentials from totally denervated muscles show a positive take-off from the base line. In the clinically normal muscles, however, only about $50 \%$ of the potentials have a negative onset.

Figure 2 shows the typical firing behaviour of a fibrillation potential from a totally denervated muscle. This highly regular firing was observed in most such potentials. However, as will be shown below, as an exception irregular firing potentials could be recorded from completely denervated muscles. Irregular firing is a typical but not invariable finding in control animal and human muscles (fig 3). Figures 4 and 5 show histograms of APCID, MCD, mean interval duration, standard deviation of intervals and interval bandwidth. The APCID-value allows of the best differentiation of individual spontaneous potentials from denervated
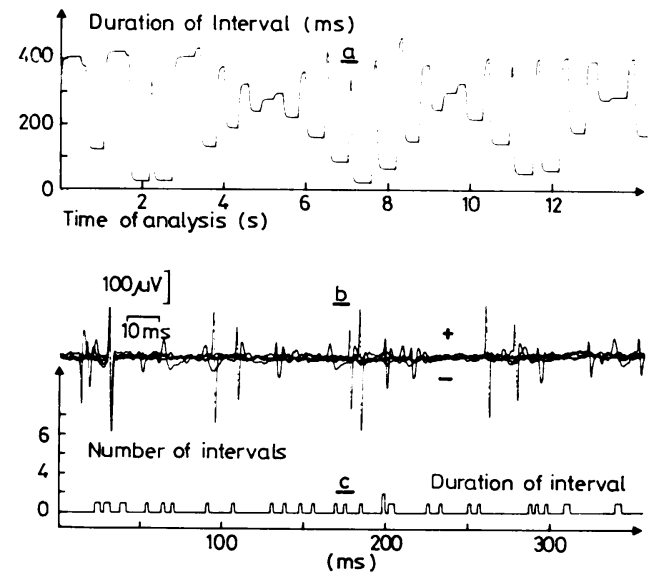

Fig 3 Typical interval behaviour of an endplate potential. A interval behaviour versus time of analysis; $B$ superposition of potentials of the analysed potential sequence; C interval histogram.

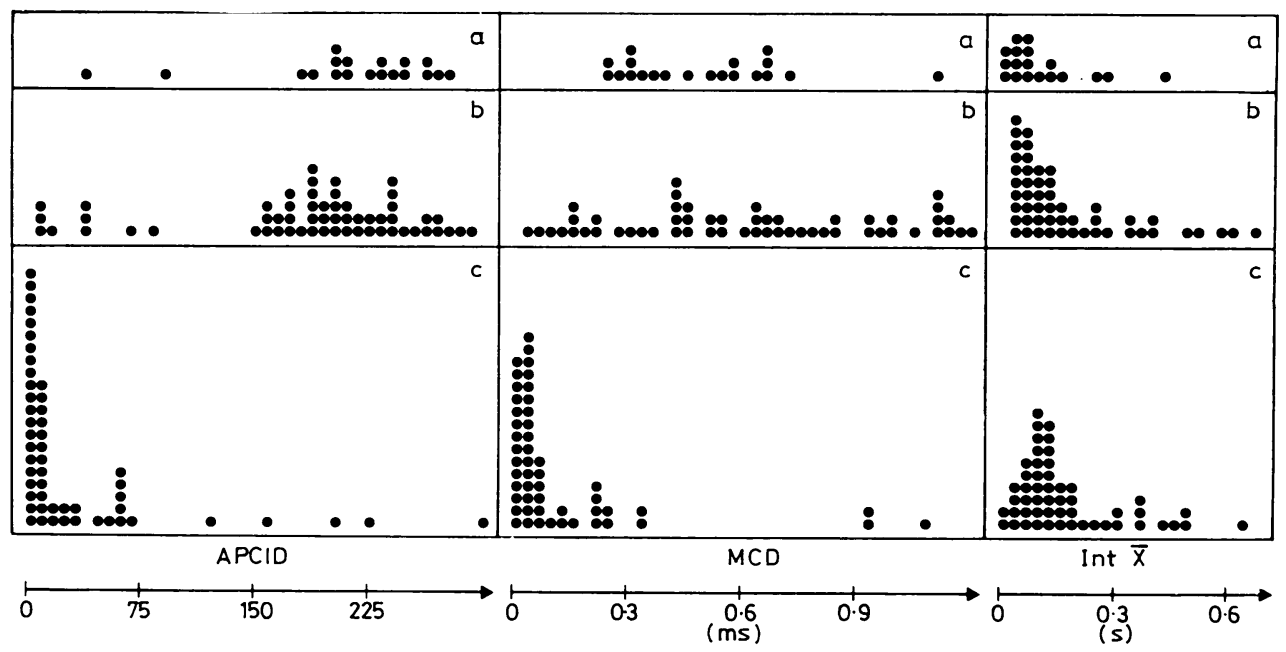

Fig 4 Histograms of APCID, MCD and mean interval duration from normal human muscle $(A)$, normal $(B)$ and denervated $(C)$ muscle of dog. 


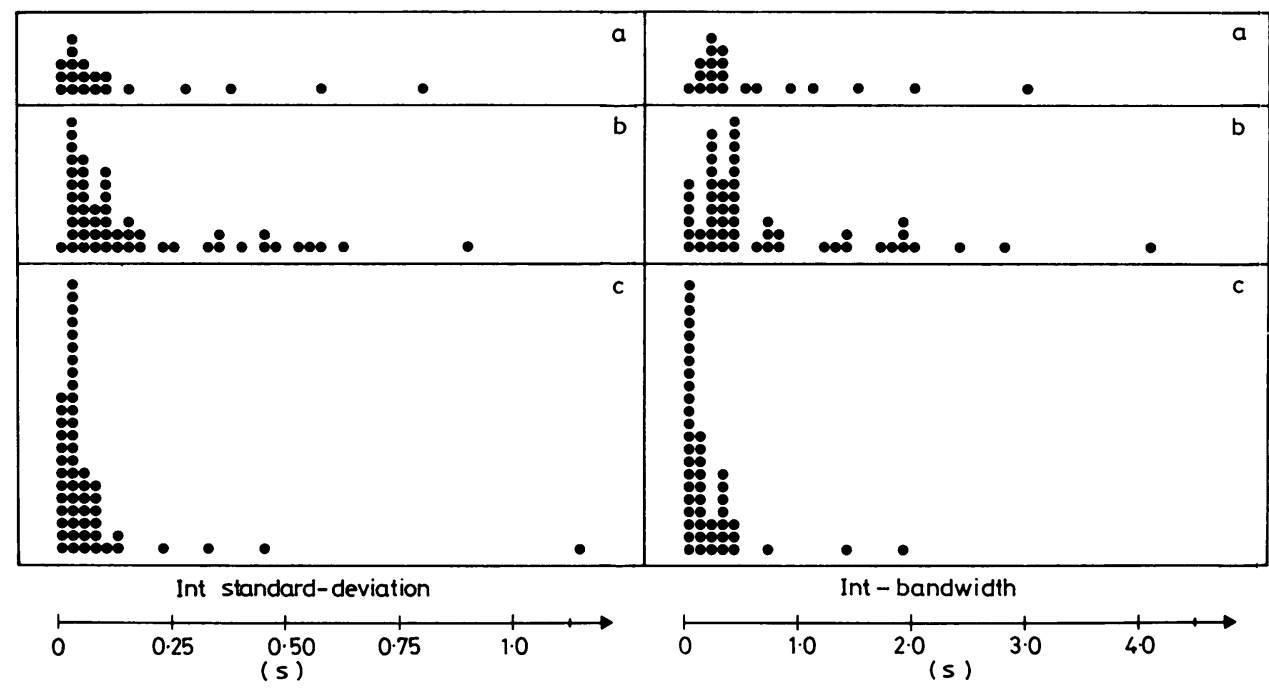

Fig 5 Histograms of standard deviation of intervals and interval bandwidth from normal human muscle $(A)$, normal $(B)$ and denervated $(C)$ muscle of dog.
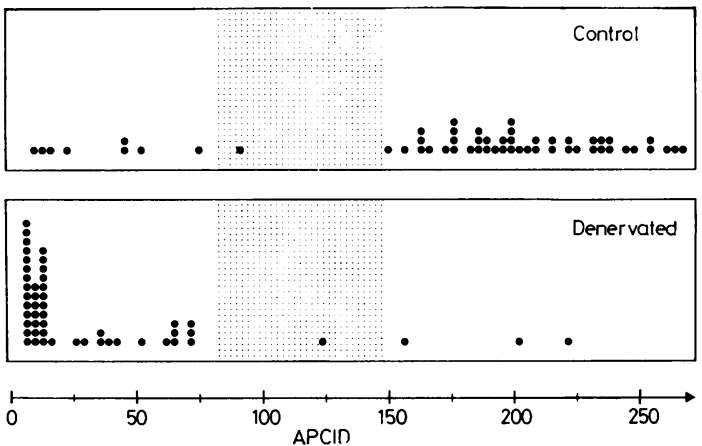

Fig 6 APCID histograms of control muscles and of totally denervated muscles of the dog. Grey field: no decision should be taken for "control" and "denervated" respectively.

and control muscle (fig 6). Values below 80 and above 150 are typical for denervated and control muscle respectively. About $90 \%$ of the potentials analysed obey this rule.

The other computed values have larger overlaps between normal and pathological values, even if they all (with the exception of the mean interval) give highly significant differences when considering the entire groups of potentials (table 2). With the variables total duration of potentials, amplitude, number of phases, APCID, MCD, interval bandwidth, mean deviation of interval, interval minimum and maximum and mean interval duration a "one way analysis of variance and covariance" was carried out. ${ }^{11}$ This showed that

- no differentiation between different groups is possible by total duration of potentials, amplitude, number of phases and mean interval duration $(\mathrm{p}<0 \cdot 15)$.

-division is possible into "denervated" (dog) and "control" (dog) by the rest of the variables $(p<0.0005)$. The reliability of differentiation decreases according to the listing of table 2 .

Table 2 Results of the frequency analysis

\begin{tabular}{|c|c|c|c|c|c|}
\hline Variables & & $\begin{array}{l}\text { Control (human) } \\
\text { (mean } \pm S D)\end{array}$ & $\begin{array}{l}\text { Control }(\text { dog }) \\
(\text { mean } \pm S D)\end{array}$ & $\begin{array}{l}\text { Denervated }(\text { dog }) \\
(\text { mean } \pm S D)\end{array}$ & $p$ value \\
\hline $\begin{array}{l}\text { APCID } \\
\text { MCD } \\
\text { Interval bandwidth } \\
\text { Deviation of interval } \\
\text { Interval minimum } \\
\text { Interval maximum } \\
\text { Mean interval } \\
\text { Number of potential sequences }\end{array}$ & $\begin{array}{l}\mathrm{ms} \\
\mathrm{ms} \\
\mathrm{ms} \\
\mathrm{ms} \\
\mathrm{ms} \\
\mathrm{ms}\end{array}$ & $\begin{array}{l}227 \cdot 5 \pm 62 \cdot 5 \\
0.50 \pm 0.22 \\
651 \cdot 7 \pm 776.6 \\
151 \cdot 5 \pm 221 \cdot 0 \\
15.4 \pm 30 \cdot 0 \\
667 \cdot 0 \pm 780 \cdot 8 \\
192 \cdot 4 \pm 262 \cdot 3 \\
20\end{array}$ & 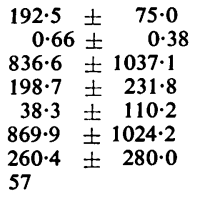 & $\begin{array}{ccc}37 \cdot 5 & \pm 65 \cdot 0 \\
0 \cdot 34 & \pm 0 \cdot 34 \\
208 \cdot 9 & \pm 336 \cdot 9 \\
61 \cdot 0 & \pm 80 \cdot 3 \\
115 \cdot 5 & \pm 126 \cdot 1 \\
326 \cdot 2 & \pm 339 \cdot 0 \\
192 \cdot 6 & \pm 185 \cdot 9 \\
52 & \end{array}$ & $\begin{array}{c}<10^{-8} \\
<10^{-4} \\
10^{-4} \\
10^{-4} \\
3 \cdot 10^{-4} \\
4 \cdot 10^{-4} \\
0 \cdot 149\end{array}$ \\
\hline
\end{tabular}


- "control" (human) and "control" (dog) are not differentiated $(p<0.05)$.

The variables were put under a stepwise discriminant analysis program: ${ }^{12}$ we found that the most significant parameter is the APCID with a discrimination accuracy of $90 \%$ per analysed sequence and that a combination of different variables did not increase the discrimination accuracy.

It is to be stressed that fibrillation potentials and sharp waves appear much earlier after severance of the peripheral nerve in canine than in human muscle. ${ }^{13}$ Four to 5 days after neurectomy positive sharp waves can be derived more frequently than fibrillation potentials from the totally denervated muscle. In ten recordings which were made after 4 to 6 weeks it was shown that the frequency behaviour of spontaneous activity remains constant. At that time, fibrillation potentials were more numerous than positive sharp waves.

The conventional evaluations of the taped spontaneous activity-paper recordings at $100 \mathrm{~ms}$ each judged in combination with the displayed spontaneous activity at a monitor-resulted in $68.2 \% \pm$ $18.5 \%$ "denervated", $51.8 \% \pm 13.2 \%$ "control" correct findings. When the paper recordings without acoustic and optic control were judged, correct findings resulted in $63.3 \% \pm 21.4 \%$ "denervated" and $57 \cdot 3 \% \pm 14 \%$ "control".

\section{Discussion}

First, the question is to be answered whether the interval behaviour of spontaneous activity is similar in human and canine muscle. A comparison between healthy human muscle and healthy animal muscle did not show any significant difference. There remains some uncertainty with regard to the totally denervated muscle since no experiments were made in the totally denervated human muscle. The animal model is advantageous because one can produce totally denervated muscle by way of a simple neurectomy. The totally denervated muscle does not have any functioning endplates. Therefore, spontaneous activity from a totally denervated muscle cannot consist of true endplate potentials. There is, however, no absolute certainty that potentials recorded from clinically healthy muscles originate from healthy muscles fibres.

Frequency analysis leads to reliable results only when fibrillation potentials are not too dense. Because different fibrillation potentials and positive sharp waves fire with different frequencies, deformation of potentials may occur by superposition so that trigger conditions are no longer fulfilled. In such cases the interval duration may be measured twofold or threefold. Totally denervated muscles were examined, therefore, until the fifth day after nerve section only. In ten control recordings it could be demonstrated, however, that the frequency behaviour was the same after 4 to 6 weeks.

As the results show, the APCID value ${ }^{8}$ represents the best differentiation parameter with an accuracy of more than $90 \%$ for each analysed potential sequence. The combination with other frequency parameters does not improve discrimination accuracy. Though minimum interval duration and maximum interval duration lead to relatively good differentiation they are unreliable values because single, incorrect triggers may bring about either too small or too large values. The mean interval duration does not allow of any differentiation. As most of the values show departures from normal distribution, the "Levene test" for equality of variances was carried out. This is a more robust test against departures from normality. ${ }^{14}$ Based on this test it can be said that the conclusions made are correct.

Even in totally denervated muscle irregularly firing potentials with APCID values of more than $150(10 \%)$ may be found. This is of great interest because there are no functioning endplates and therefore no true endplate potentials either. The APCID value allows of a differentiation accuracy of $90 \%$ if one potential sequence is considered. If three potential sequences are analysed for a given muscle the accuracy is significantly improved. Two out of three potentials with an APCID value below 80 or above 150 give a $97.2 \%$ probability that the muscle examined is (partially) denervated or normal respectively. In addition to the frequency behaviour, we also analysed shape parameters of the potentials. We have found that the take-off from the base line is the only shape parameter that can contribute to discrimination. But this value alone is a relatively weak criterion to characterise the potentials. It can only be said that a negative onset occurs rarely in denervated muscle. A quality comparison with the other variables cannot be done because the polarity of the initial deflection of potentials is a binary value and therefore it cannot be handled by the statistical procedures mentioned.

The conventional evaluation of the potential sequence at the monitor combined with acoustic control and the evaluation of registered sequences is much less reliable than the frequency analysis. This latter method delivers about $60 \%$ correct and $40 \%$ incorrect results. There is no implication, however, that there is a corresponding amount of wrong decisions under clinical conditions. It is comparatively easy to diagnose a totally denervated muscle by electromyography or even an only partially denervated one, if the degree of denervation is not too low. There are difficulties, however, when 
discrete denervations are to be assumed. In such cases, one is looking for spontaneous activity but according to our experience, one does not find typical "endplate potentials" only, even in a clinically normal muscle.

We thank $\mathrm{H}$ Hogg for development and construction of electronic data processing equipment, E Eggenberger, E Hunziker, Th Wiestner for counselling on statistical problems and for evaluating data, P Oettli for assistance during the various experiments, $M$ Becker for the execution of the neurectomies.

\section{References}

${ }^{1}$ Buchthal F, Rosenfalck P. Spontaneous electrical activity of human muscle. Electroencephalogr Clin Neurophysiol 1966;20:321-36.

${ }^{2}$ Denny-Brown D, Pennybacker JB. Fibrillation and fasciculation in voluntary muscle. Brain 1938;61: 311-44.

3 Jasper H, Ballem G. Unipolar electromyograms of normal and denervated human muscle. $J$ Neurophysiol 1949;12:231-43.

4 Jones RV, Lambert EH, Sayre GP. Source of a type of "insertion activity" in electromyography with evaluation of histological method of localization. Arch Phys Med 1955;36:301-10.
${ }^{5}$ Ludin HP. Electromyography in Practice. Stuttgart and New York: Thieme, 1980.

${ }^{6}$ Ludin HP. Pathophysiologische Grundlagen elektromyographischer Befunde bei Neuropathien und Myopathien, 2. überarbeitete Auflage. Stuttgart: Thieme, 1977.

7 Tower S, Howe H, Bodian D. Fibrillation in skeletal muscle in relation to denervation and to inactivation without denervation. $J$ Neurophysiol 1941 ;4:398-401.

${ }^{8}$ Conrad B, Sindermann F, Prochazka VJ. Interval analysis of repetitive denervation potentials of human skeletal muscle.J Neurol Neurosurg Psychiatry 1972;35:834-40.

${ }^{9}$ Stöhr E. Benign fibrillation potentials in normal muscle and their correlation with endplate and denervation potentials. J Neurol Neurosurg Psychiatry 1977;40:765-8.

${ }^{10}$ Stålberg E, Eckstedt J, Broman A. The electromyographic jitter in normal human muscles. Electroencephalogr Clin Neurophysiol 1971;31:42938.

${ }^{11}$ Brown MB, Forsythe AB. The small sample behaviour of some statistics which test the equality of several means. Technometrics 1974;16:129-32.

12 Fisher RA. The statistical utilization of multiple measurements. Ann Eugenics 1938;8:376-86.

13 Brown MB, Forsythe AB. Robust tests of equality of variances. J Am Statist Assoc 1974;69:364-7.

14 Heckmann R. Beitrag zur Elektromyographie in der Veterinärmedizin. Zbl Vet Med A 1975:22;713-40 